Full length article

\title{
Distinct $\beta$-glucan molecules modulates differently the circulating cortisol levels and innate immune responses in matrinxã (Brycon amazonicus)
}

\author{
Luz Natalia Franco Montoya ${ }^{\mathrm{a}, 1}$, Gisele Cristina Favero ${ }^{\mathrm{a}, 2}$, Fabio Sabbadin Zanuzzo ${ }^{\mathrm{b}, 3}$, \\ Elisabeth Criscuolo Urbinati ${ }^{\mathrm{a}, \mathrm{b}, *}$
}

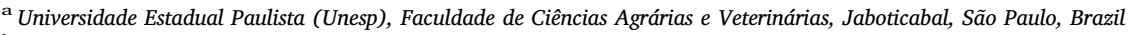

${ }^{\mathrm{b}}$ Universidade Estadual Paulista (Unesp), Centro de Aquicultura da Unesp, Jaboticabal, São Paulo, Brazil

\section{A R T I C L E I N F O}

\section{Keywords:}

Immunostimulation

Cell-mediated immunity

Early defense

White blood cells

\begin{abstract}
A B S T R A C T
This study investigated the effects of two $\beta$-glucan molecules with different purities and isolated by different biotechnological processes on the immune response of matrinxã (Brycon amazonicus) prior and after challenge with Aeromonas hydrophila. In this sense, we evaluated serum cortisol and plasma glucose levels, the number of leukocytes (lymphocytes, neutrophils and monocytes), as well as the respiratory activity of leukocytes prior to, 6 and $24 \mathrm{~h}$ post infection (hpi). During 15 days, fish were fed with diets containing $0.1 \%$ of two $\beta$-glucans ( $\beta$-G 1 and $\beta-G 2$, with 71 and $62 \%$ of purity, respectively) and then submitted to challenge. Results were compared with a positive control group fed with a $\beta$-glucan-free diet. A negative control group, also fed with $\beta$-glucan-free diet but inoculated with PBS, was established to evaluate the effect of handling during injection. Our results showed that different $\beta$-glucans affected differently the biological responses of matrinxã. The $\beta G 2$ modulated the cortisol profile prior to and after the acute infection with A. hydrophila, and increased the mobilization and activity of leukocytes. The infection promoted lymphopenia at $6 \mathrm{hpi}$ and both $\beta$-glucans increased the circulating lymphocyte population 24 hpi. Moreover, the $\beta-G 2$ prevented the infection-induced neutrophilia at 6 and 24 hpi. Finally, the $\beta-G 2$ caused a marked increase in the circulating monocytes prior to infection, and a reduction at $6 \mathrm{hpi}$ that was reversed at $24 \mathrm{hpi}$. In summary, our study demonstrates that $\beta-\mathrm{G} 2$ was more efficient on the induction of the cell-mediate immunity in matrinxã.
\end{abstract}

\section{Introduction}

Modern intensive aquaculture can adversely affect the health of cultured fish by promoting a potentially stressful environment and the growth of infectious diseases. Unfortunately, the indiscriminate use of antibiotics and other drugs to control diseases has contributed to the emergence of several resistant pathogenic organisms [1]. Therefore, efforts aiming to develop strategies to control the pathogen and immuno-prophylactic measures are needed to support the economic viability of the activity.

Dietary addition of immunostimulants has been shown to enhance fish innate humoral and cellular immune responses against infectious diseases [2-5]. These substances induce the proliferation of leukocytes and their phagocytic activity, as well as secretion of immune mediators such as cytokines [6]. Among these immunostimulants are the $\beta(1-3)$ (1-6)-D-glucans, hereafter referred to as " $\beta$-glucans", which are highly conserved carbohydrates found in the cell walls of plants, fungi, yeast, seaweed, and bacteria $[7,8]$. They consist of a backbone of $\beta-(1,3)$ linked $\beta$-D-glucopyranosyl units with $\beta$ - $(1,6)$-linked side chains of varying distributions and lengths $[3,6,9]$. The $\beta$-glucan from the cell wall of Saccharomyces cerevisiae has been shown to have immunostimulatory and beneficial properties, including enhanced protection against infections [10], tumor development [11], and sepsis $[12,13]$. Its effect has been attributed to the binding to multiple toll-like receptors on leukocytes membrane, resulting in the stimulation of immune responses, such as the increase of bactericidal activity [2] and modulation of cytokine production [14].

Several $\beta$-glucans are now commercially available to be

\footnotetext{
* Corresponding author. Universidade Estadual Paulista (Unesp), Faculdade de Ciências Agrárias e Veterinárias, Jaboticabal, São Paulo, Brazil.

E-mail addresses: nataliafranco@utp.edu.co (L.N. Franco Montoya), giselefav82@yahoo.com.br (G.C. Favero), fabioz@mun.ca (F.S. Zanuzzo), bethurb@fcav.unesp.br, bethurb@uol.com.br (E.C. Urbinati).

${ }^{1}$ Current address: Universidad Tecnológica de Pereira, Facultad de Ciencias de la Salud, Departamento de Ciencias Basicas, Pereira, Risaralda, Colombia.

${ }^{2}$ Current address: Universidade Federal de Minas Gerais (UFMG), Campus Pampulha, Belo Horizonte, MG, Brazil.

${ }^{3}$ Current address: Memorial University of Newfoundland, Department of Ocean Sciences, St. John's, NL, Canada.
} 
incorporated in the diets of livestock, including farmed fish $[6,15]$. The activation of the immune response by the $\beta$-glucans depends on their molecular weight and degree of branching and the extraction process has implications for the benefits of these compounds $[16,17]$. However, few are known about the comparative efficiency of $\beta$-glucans extracted by different biotechnological methods, as immunostimulants able to strengthen defense mechanisms $[18,19]$. Therefore, we compared the effects of two insoluble $\beta$-glucan molecules over the immune response in matrinxã, a teleost fish from the Amazon basin, with high economic value for aquaculture in some South American countries [20]. In order to achieve our aim, fish previously fed with $\beta$-glucans were experimentally inoculated with Aeromonas hydrophila, a gram-negative bacterium that is commonly isolated from freshwater environment and used to stimulate immune responses in fis [21]. The results presented herein offer new knowledge about the immunostimulant effects of $\beta$ glucan molecules as well as feed strategies to increase disease resistance and improve fish health.

\section{Material and methods}

\subsection{Experimental animals and lab condition}

This study utilized 64 juvenile fish $(250.9 \pm 45.9 \mathrm{~g}$ and $25.7 \pm 1.4 \mathrm{~cm}$ ) that were kept individually in 64 40-liter fiber tanks ( 1

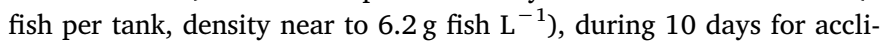
matization to the laboratorial conditions being fed with a commercial feed ( $28 \%$ crude protein $\mathrm{CP}$ ). Temperature, oxygen and ammonia levels were $30^{\circ} \pm 0.4^{\circ} \mathrm{C}, 5.7 \pm 0.2 \mathrm{mg} \mathrm{L}^{-1}$, and $71.1 \pm 21.2 \mu \mathrm{gL}^{-1}$, respectively. Photoperiod was $14 \mathrm{~h}$ light: $10 \mathrm{~h}$ dark, during summer season.

\subsection{Experimental design and diets}

The present study evaluated the individual immunostimulant effect of the two $\beta$-glucan molecules ( $\beta$-G 1 and $\beta-G$ ) added to a rate of $0.1 \%$ in commercial feed $(28 \% \mathrm{CP})$ and their effects were compared with a $\beta$ glucan-free diet as positive control. The matrinxa displays a highly aggressive behavior [22], and fish were allocated in individual tanks in order to avoid agonistic behavior which could drastically affect the stress and immune responses. After acclimatization, fish were fed with $1.5 \%$ of their body mass twice a day (11:00-16:00 $\mathrm{h}$ ) during 15 days. We used 18 fish per treatment (Control, $0.1 \% \beta-G 1$ and $0.1 \% \beta-G 2$ ). Another 10 fish were fed with the control feed to represent the negative control group that would be inoculated with phosphate buffered saline solution (PBS) in instead of bacterial inoculation. On the 16th day, six fish were sampled to determine the prior infection condition. Following that, 12 fish per treatment, starved for $12 \mathrm{~h}$, were anesthetized (benzocaine, $0.05 \mathrm{~g} \mathrm{~L}^{-1}$ ) and inoculated in the mesenteric cavity with a sub lethal concentration of $A$. hydrophila $\left(2.5 \mu \mathrm{Lg}^{-1}\right)$, while the 10 fish from the negative control group were inoculated with PBS. At 6 and $24 \mathrm{~h}$ post infection (hpi), anesthetized fish were bled in order to evaluate biochemical and cellular indicators of their immunological condition.

Experimental diets were prepared using an extruded commercial feed that was ground, and to which $0.1 \%$ of two different glucans coded as $\beta-G 1$ and $\beta-G 2$ were incorporated. Then, in order to re-pelletize the feed, the mixture was moistened with $40 \%$ water, passed through a food processor, and finally dried in an oven with air extraction at $40{ }^{\circ} \mathrm{C}$ for $24 \mathrm{~h}$. The control feed was $\beta$-glucan-free. The two $\beta$-glucans were isolated from Saccharomyces cerevisiae, being $\beta$-G1 Macrogard 71\% pure (batch number Q513187) and $\beta-G 2$ is a research and development substance for now called "R\&D $\beta$-glucan" $62 \%$ pure (batch number T1411201). Both products contain $\beta$-glucans plus lipids, protein, ash and moisture, and no nucleotides according to the manufacturer. The batches were kindly provided by Biorigin, Brazil; (http://www.biorigin. net/biorigin/macrogard/macrogard_en/index.html).

\subsection{Acute bacterial challenge}

The A. hydrophila strain was isolated from carp Cyprinus carpio (strain A135, LAPOA, UNESP) and identified by sequencing of the 16S rDNA (similarity of $97 \%$ with GenBank access: ATCC 7966). The strain was stocked in TSB (Tryptic Soy Broth, Media) medium with $30 \%$ glycerol (sterile), at $-80{ }^{\circ} \mathrm{C}$. An aliquot of $20 \mu \mathrm{L}$ (strain stock) was inoculated in $5 \mathrm{~mL}$ of autoclaved TSB medium and incubated in bacteriological incubator at $28{ }^{\circ} \mathrm{C}$, for $24 \mathrm{~h}$. Subsequently, $200 \mathrm{~mL}$ of autoclaved TSB medium was added and incubated again with the same procedure. The bacterial suspension was centrifuged at $8.000 \times \mathrm{g}$ for $10 \mathrm{~min}$ and supernatant was discarded. Then PBS buffer $(0.01 \mathrm{M})$ was used to wash the pellets twice and the suspension was centrifuged again. The bacterial PBS suspension was lower than the lethal concentration CL $50\left(7.6 * 10^{8} \mathrm{CFU} \mathrm{mL}{ }^{-1}\right)$ adjusted by the UFC counting after bacterial culture and determined based on the optical density (OD600 = 1.095), using PBS buffer $(0.01 \mathrm{M})$. For stimulation of the fish immune response, the bacterial suspension was previously determined as a sub lethal dose (pre-experimental tests, data not shown). No mortality was recorded during the experiment period.

\subsection{Sampling}

At each sampling time, 6 fish per treatment (different fish at each sampling time were used) were anesthetized and blood samples were drawn from the caudal vein using syringes without anticoagulant. Blood was dispensed in $2 \mathrm{~mL}$ microtubes with and without anticoagulant. Blood with the anticoagulant Glistab ${ }^{\circ}$ was maintained under refrigeration for plasma glucose determination and NBT activity measure. The blood smears preparations were made with fresh blood. Blood in microtubes without anticoagulant was maintained at room temperature for $3 \mathrm{~h}$ and then centrifuged ( $3000 \mathrm{rpm}$ for $5 \mathrm{~min}$ ) for serum separation. Serum samples were stored at $-20^{\circ} \mathrm{C}$ and further used to measure cortisol levels.

\subsection{Serum cortisol and plasma glucose concentrations}

Blood cortisol concentration was measured by enzyme-linked immunosorbent assay (ELISA) with a commercial kit (DRG ${ }^{\bullet}$ Cortisol ELISA, EIA-1887; DRG International, Inc., USA; http://www.drginternational.com). The plasma glucose concentrations were measured by enzymatic method (Labtest kit, Sao Paulo, Brazil, code 84) following the instructions of the manufacturer.

\subsection{Leukocyte respiratory burst - NBT activity}

The production of reactive oxygen species (ROS) was measured using NBT (Nitro tetrazolium blue chloride - Sigma Aldrich - N6876), following protocol by Anderson \& Siwicki (1995) [23], modified by Biller-Takahashi et al. (2013) [24]. Immediately after fish bleeding, $50 \mu \mathrm{L}$ of heparinized blood was incubated with an equal volume of NBT buffer $(0.2 \%)$ at room temperature for $30 \mathrm{~min}$. Subsequently, $1 \mathrm{~mL}$ of DMF (Dimethylformamide, Sigma Aldrich - 227056) was added to the samples, and they were read using a spectrophotometer (Thermo Scientific; Genesys 10S), at room temperature, at $540 \mathrm{~nm}$.

\subsection{Cellular counts}

The total count of red cells was performed in a Neubauer chamber, using whole blood diluted in formaldehyde citrate buffer 1:200. The total and differential count of leukocyte was performed using optical microscopy on blood smears stained with methanol blue eosin solution May-Grünwald-Giemsa-Wrigth (MGGW), according to [25]. The leukocytes were measured by the indirect method, which considers the number of leukocytes for 2000 erythrocytes counted. To the leukocytes differentiation, 200 cells were counted and the amount of each cell type 
was expressed as cells $\mu 1^{-1}$.

\subsection{Data analysis}

To evaluate the immunostimulant effect of both $\beta$-glucans and to compare the control group prior to and after bacterial challenge all data was submitted to normality (Shapiro-Wilk) and homoscedasticity (Levene). A two-way-ANOVA was used with a factorial of $3 \times 3$, being 3 treatments (positive control, $\beta-G 1^{\circ}$ and $\beta-G 2^{\circ}$ ) $\times 3$ sampling times (prior to infection, $6 \mathrm{hpi}$, and $24 \mathrm{hpi}$ ). Duncan's post-hoc tests were made for comparison of means. Finally, a $t$-test was used to compare the means of positive and negative control groups 6 and $24 \mathrm{~h}$ after the respective inoculations. Values in the text and figures are represented by means \pm standard error (SE) of the mean. $\mathrm{P}$ value $<0.05$ was used to estimate the level of significance for statistical differences.

\subsection{Ethical statemen}

All procedures that involved animal use were performed in accordance with ethical principles in animal experimentation, adopted by the Colégio Brasileiro de Experimentação (COBEA), Brasilia, Brazil, and approved by the Comissão de Ética no Uso de Animais (CEUA) protocol $n^{\circ}$ 014679/14 UNESP - Jaboticabal campus.

\section{Results}

To evaluate the immunostimulant effect of two $\beta$-glucan molecules ( $\beta-G 1$ and $\beta-G 2$ ) on the induction of fish immune response, matrinxã juveniles were fed for 15 days with or without the $\beta$-glucans before being inoculated with $A$. hydrophila. Biochemical and cellular indicators were evaluated just before inoculation and again 6 and $24 \mathrm{~h}$ after inoculation.

\subsection{Blood cortisol and glucose concentrations}

Prior to infection, fish fed with $\beta-G 2$ showed the highest levels of serum cortisol, followed by animals fed with $\beta-G 1$ and lastly by the positive control group. Fish from the positive control group presented similar serum cortisol levels $6 \mathrm{~h}$ post infection (hpi). However, cortisol levels were higher in fish fed with $\beta-G 2$ compared to fish fed with $\beta-G 1$ $(\mathrm{P}<0.05)$, or the positive control diet $(\mathrm{P}<0.001)$. Only fish fed with the $\beta$-glucans reduced cortisol levels at $24 \mathrm{hpi}$, when compared to the levels measured prior to infection and at $6 \mathrm{hpi}$. Serum cortisol levels in fish of the negative control group were always lower than those of the positive control (Fig. 1A).

Prior to infection, plasma glucose concentrations did not differ among treatments. However, at $6 \mathrm{hpi}$ all the challenged fish had reduced plasma glucose concentrations $(\mathrm{P}<0.05)$. At $24 \mathrm{hpi}$, the glucose levels of fish fed with $\beta-G 1$ were higher than those observed in the positive control group; fish fed with $\beta-G 2$ revealed intermediate values. Negative control glucose values did not differ between 6 and $24 \mathrm{~h}$ after PBS inoculation, being higher at 6 hpi compared to the positive control group (Fig. 1B).

\subsubsection{Respiratory activity of leukocytes (RAL)}

Prior to infection, RAL did not differ among treatments. However, at $6 \mathrm{hpi}$, we observed increase in the reactive oxygen species (ROS) in all challenged fish. Furthermore, this increase was higher in fish fed with $\beta-G 2$ followed by fish from the positive control group and lastly by fish fed with $\beta-G 1$. At this sampling time, RAL did not differ between fish from positive and negative control groups. Twenty-four hpi, RAL returned to the initial values in all treated fish, but remained higher in fish from the negative control group compared to the positive control group (Fig. 2).
Positive control
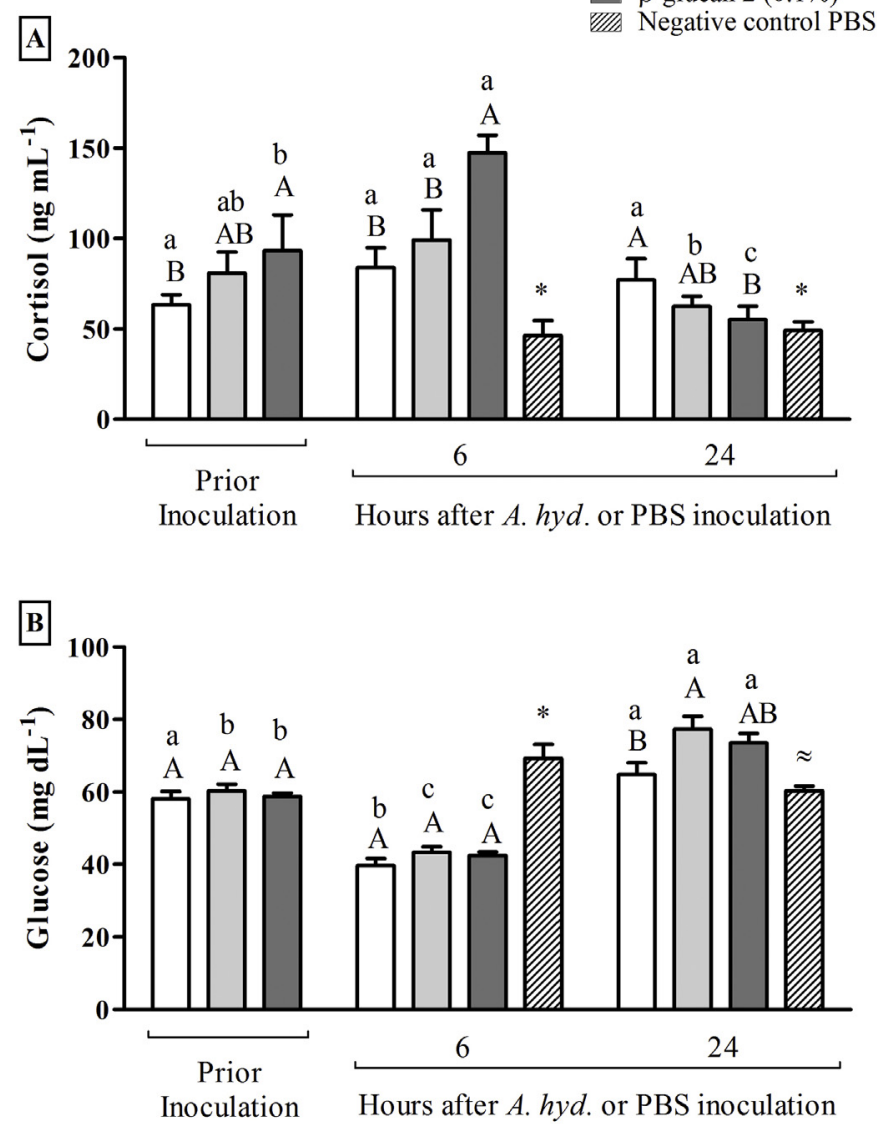

Fig. 1. Serum cortisol (A) and plasma glucose concentrations (B) in matrinxã. Fish fed with $\beta-G 1$ and $\beta-G$ 2. The results are compared to fish from positive (bacterial challenge) and negative (PBS injected) control groups, prior to and after A. hydrophila inoculation. Different capital letters indicate differences between treatment groups in each isolated sampling time. Different lowercase letters indicate differences between the readings of the same treatment group, collected at all times shown. Symbols, $\approx$ indicates no difference and * indicates difference between positive and negative control groups 6 and 24 hpi. Columns represent the means $\pm \operatorname{SEM}(\mathrm{n}=6, \mathrm{P}<0.05)$.

\subsection{Number of circulating leukocytes, lymphocytes, neutrophils and monocytes}

Prior to infection, the number of leukocytes did not differ among treatments. However, at $6 \mathrm{hpi}$, there was a drop of approximately $42 \%$ in the number of these circulating cells, being lower in fish fed with $\beta-G$ $2(\mathrm{P}<0.05)$. At $24 \mathrm{hpi}$, the number of leukocytes was around $38 \%$ lower than the initial values. At 6 and $24 \mathrm{hpi}$, fish from the negative control group showed lower numbers of leukocytes than the positive control group (Fig. 3A).

Prior to infection, the number of lymphocytes did not differ among treatments. However, at $6 \mathrm{hpi}$, all fish from challenged groups showed a drop of approximately $83 \%$ in the number of circulating lymphocytes $(\mathrm{P}<0.0001)$. Fish from the negative control group presented higher number of lymphocytes than those from the positive control group. At $24 \mathrm{hpi}$, all challenged fish revealed an increase in the number of lymphocytes. However, fish fed with both $\beta$-glucans (1 and 2) showed higher circulating lymphocytes values compared to the positive and negative controls $(P<0.05)$, indicating an immune modulation by $\beta$ glucan (Fig. 3B).

Prior to infection, the number of circulating neutrophils did not differ among treatments. However, at $6 \mathrm{hpi}$, these levels rose markedly 

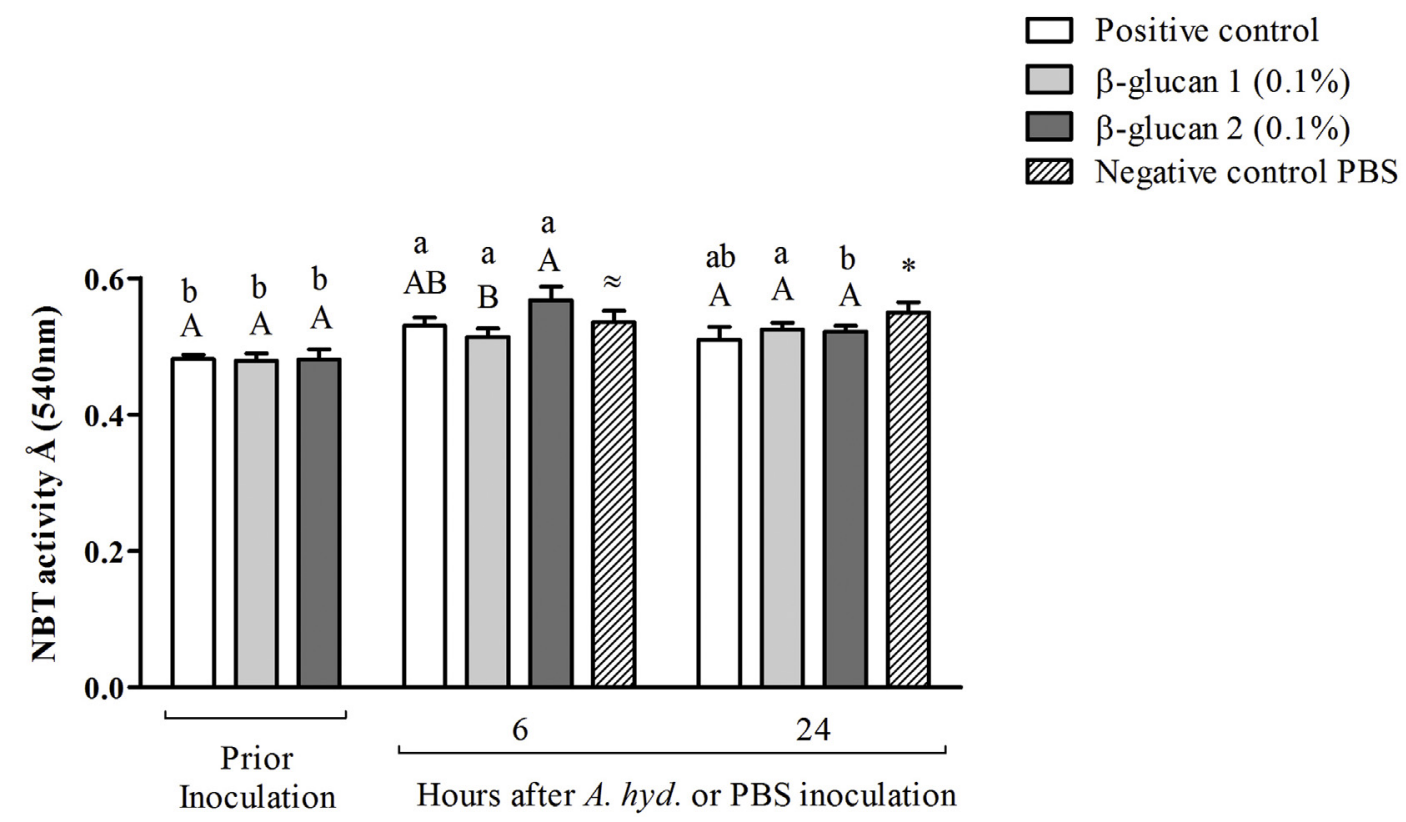

Fig. 2. Respiratory activity of leukocytes in matrinxã. Fish fed with $\beta-G 1$ and $\beta-G ~ 2$. The production of reactive oxygen species was measured using nitro blue tetrazolium (NBT) (see Methods). The results are compared to fish from positive (bacterial challenge) and negative (PBS injected) control, prior to and after A. hydrophila inoculation. Different capital letters indicate differences between treatment groups in each isolated sampling time. Different lowercase letters indicate differences between the readings of the same treatment group, collected at all times shown. Symbols, $\approx$ indicates no difference and * indicates difference between positive and negative control groups 6 and $24 \mathrm{~h}$ post infection. Columns represented the means \pm SEM $(\mathrm{n}=6, \mathrm{P}<0.05)$.

in all fish groups, reaching a fivefold increase in fish from the positive control and the $\beta-G 1$ group $(P<0.05)$. Fish fed with $\beta-G 2$ also showed increased number of these cells, albeit lower than fish from the two groups aforementioned. At $24 \mathrm{hpi}$, the number of circulating neutrophils reduced in all challenged groups; the reduction was more evident in fish fed with $\beta-G 2$ than in those fed $\beta-G 1$. Fish from the negative control group showed lower numbers of these cells than the positive control group in both samplings (Fig. 3C).

Prior to infection, fish fed with $\beta-G 2$ showed the highest number of circulating monocytes, followed by fish fed with $\beta-G 1$ and lastly by fish from the positive control group. At 6 and $24 \mathrm{hpi}$, only fish fed with $\beta-\mathrm{G}$ 2 showed a drop of $83 \%$ ( $<<0.0001$ ), and $60 \%$, respectively. Fish from the negative control group showed lower number of these cells than the positive control group in both samplings (Fig. 3D).

\section{Discussion}

Herein we tested the immunostimulant effect of two different $\beta$ glucan molecules on the immune response of matrinxã. The results showed that the molecules differed in their biological potency and $\beta-G$ 2 was more efficient in elevating the cortisol serum levels and stimulating the innate immune response, prior to and after an acute experimental infection.

The description of $\beta$-glucan effects over cortisol serum levels in baseline conditions in fish is still minimal. In rainbow trout, physiological cortisol serum levels did not change in fish fed with $0.1 \%$ of $\beta$ glucan during four weeks [26]. Similarly, Pangasianodon hypophthalmus fed with different concentrations of $\beta$-glucan during 9 weeks also did not show changes in the levels of circulating cortisol [27]. We observed that in matrinxã fed with $\beta-G 2$ high levels of cortisol were maintained at $6 \mathrm{hpi}$. This profile may represent a mechanism to elicit an immune response in order to prepare fish to fight against immune challenges. At $24 \mathrm{hpi}$, serum cortisol levels decreased in fish fed with both $\beta$-glucans, especially in the $\beta-G 2$ group reinforcing the modulating effect of $\beta-G 2$ on cortisol serum levels. The separate/individual effects of cortisol and $\beta$-glucans on the modulation of immune response are well characterized in fish $[2,6,28,29]$.
Our results are the first evidence that $\beta$-glucan can modulate blood cortisol level in resting condition. This can be explained because $\beta$ glucan has been recognized as a major fungal pathogen-associated molecular pattern (PAMP) [2,30]. For this reason, when $\beta$-glucan binds to receptors it can be similar to pathogen stimuli that lead to activation of monocyte/macrophages system which increases IL-6 expression and activates the hypothalamus/hypophysis/interrenal (HHI) axis and the cortisol secretion. In fish, a direct association between bacterial infections or treatment with lipopolysaccharide (LPS; bacterial cell walls components of Gram-negative bacteria) with induction of cortisol levels has been described. For instance, Oreochromis mossambicus injected with LPS from Escherichia coli showed modulation of the HPI axis at the level of the cortisol producing tissue, as well as the corticotropic release hormone CRH production on the ventral telencephalon tissue [31].

Hypoglycemia was detected after challenge with A. hydrophila (6 hpi) in all infected fish, suggesting that there was an energetic cost to elicit the immunological response in matrinxã. Recently, a previous study showed that immune responses in pacu (Piaractus mesopotamicus) has a high energetic cost reflected by decrease of the plasma glucose levels [32]. However, at $24 \mathrm{hpi}$, the glucose levels increased in all challenged fish, indicating a recovery of the energetic condition of fish after infection, regardless of dietary treatment.

$\beta$-glucans as a PAMP have strongly influenced the natural and adaptive host immune responses $[2,30]$. On the other hand, $\beta$-glucans are also known as leukocyte activators that promote immune protection in several animal disease models [15]. Herein we found that dietary $\beta-G$ 2 modulated leukocyte response in all infected fish by increasing the number of the circulating leukocytes and by mobilizating them to the infection site.

The immune modulator effect of glucans occurs following their binding to specific receptors in monocytes/macrophages, neutrophils and natural killer cells [33]. Indeed, $\beta$-glucan binds to different types of receptors $(\beta \mathrm{GR})$ in leukocytes, thereby triggering both innate and adaptive immune response [2]. Among these $\beta G R$ is the scavenger receptor that binds to anionic $\beta$-glucans (sulphated $\beta$-glucans) (for a review see Meena et al., 2013). The complement receptor 3 (CR3) is more expressed in neutrophils, monocytes, and $\mathrm{NK}$ cells compared to 

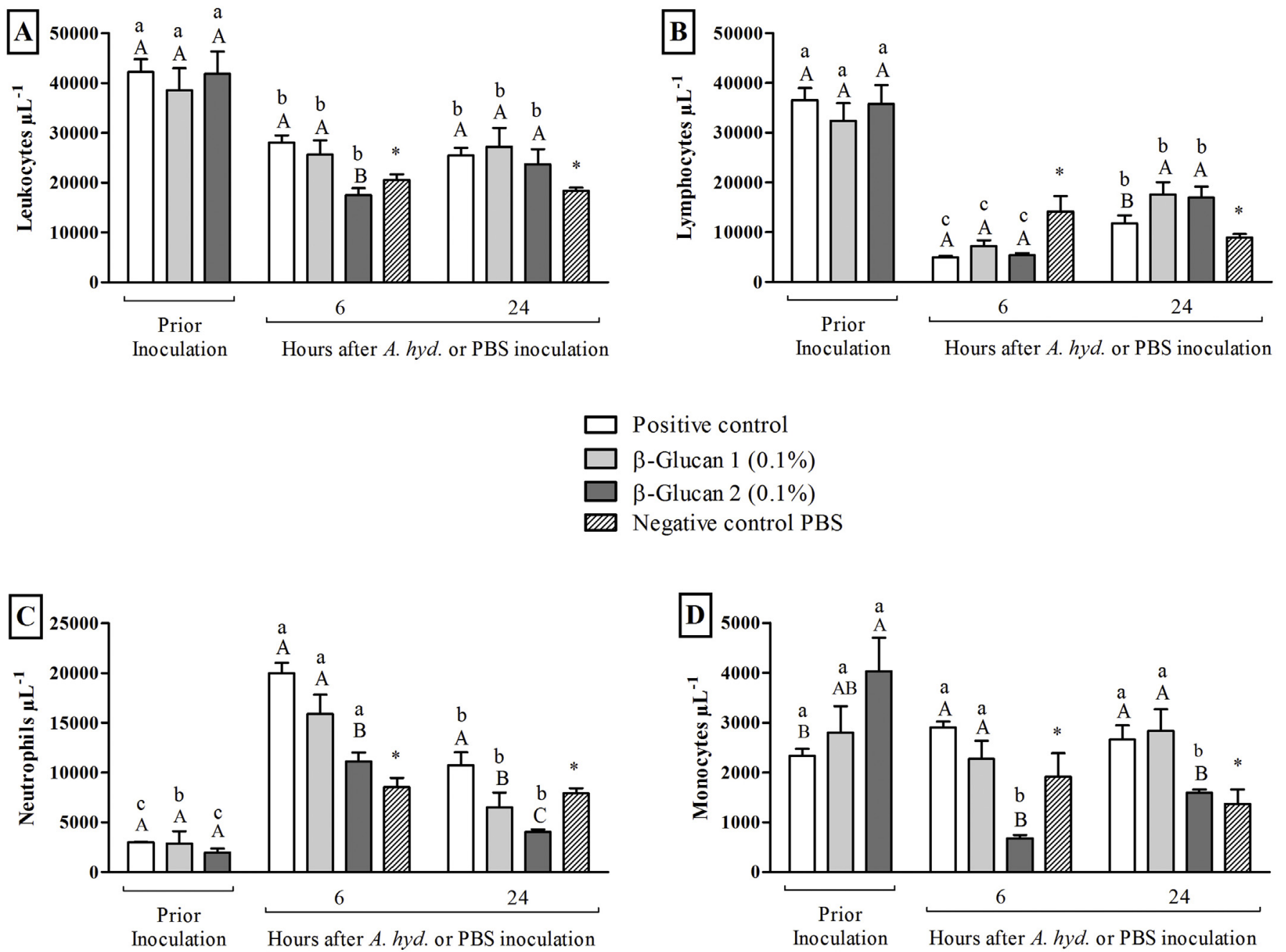

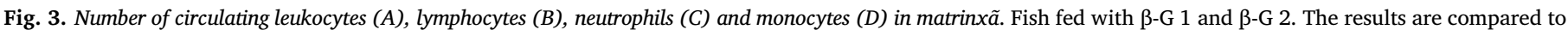

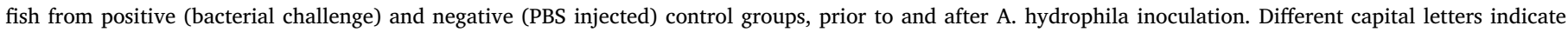

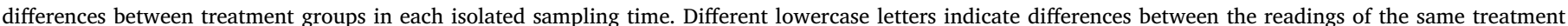

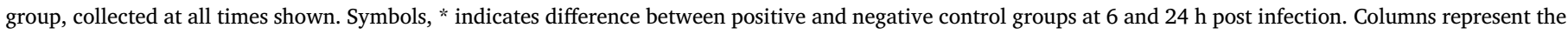
means \pm SEM $(n=6, P<0.05)$.

macrophages. Binding of $\beta$-glucan to CR3 increases leukocytes' phagocytosis and degranulation as well as their tumoricidal activity [34]. Lactosylceramide is a glycosphingolipid found on leucocytes and endothelial cells which binds to $\beta$-glucan and is associated with production of reactive oxygen species (ROS) [4]. In addition, there are various types of Toll-like receptors (TLR2-6). These receptors are used by fungal, glucans and zymosan, all of which induce cytokines after binding to TLR2 and TLR4, thereby favoring Th1 cell differentiation [2]. Lastly, the dectin-1 $\beta$ GR (dentritic cell-associated C-type lectin-1) is considered the main $\beta$-glucan receptor and it recognizes carbohydrates containing $\beta-1,3$ and/or $\beta-1,6$ glucan linkages, being expressed by monocyte/macrophages, neutrophils, dendrite cells, and T cells [30]. In carp, macrophages recognized $\beta$-glucans by multiple pattern recognition receptors that could include TLR but also non-TLR receptors and they were less, but not unresponsive, to selective dectin-1 agonists [35].

In our study, RAL increased in all challenged fish, particularly in those fed with $\beta-G 2$ at 6 hpi, which coincided with the reduction in plasma glucose levels, indicating that the fish mobilized energetic blood substrate to support higher immune cell activity. RAL increases were also observed in carp intraperitoneally injected with $\beta$-glucan [10] and in vitro, in Salmon salar macrophages [36]. The phagocytic activity of fish leukocytes is one of the most important immune mechanisms for surviving to pathogen infection [29]. The RAL is an important indicator of the phagocytic activity. The increase in oxygen uptake at the initiation of the respiratory burst is followed by the production of reactive oxygen species which plays a role in the destruction of pathogens [24].

Total leukocyte counting reflected the counting of specific white cell types. It is well known that, during the acute stage of an infection or in conditions of immune exhaustion, there is a suppression of circulating lymphocytes [37]. Moreover, in teleost fish it was demonstrated that B cells have potent in vitro and in vivo phagocytic activities [38,39]. Accordingly, after bacterial inoculation, there was a strong lymphopenia caused by the acute infection that was reversed at $24 \mathrm{hpi}$, especially in fish fed with both $\beta$-glucans. Therefore, it is plausible to suggest that there was a migration process stimulated by the immune activation and the reversal was due to immunostimulation by $\beta$-glucans that increased these cells' population. In contrast with our results, feeding sea bass Dicentrarchus labrax with Macrogard 0.1\% during 60 days did not stimulate the lymphocytes populations [40].

Leukocyte profile was inversely associated to levels of serum cortisol, except in the case of lymphocytes. In fish, cortisol has been shown to affect the number of circulating leukocytes and their activity [29,41-43]. However, different cells of the immune systems show varied responses to cortisol [41]. Previous studies have described cortisol induced lymphopenia and reduced lymphocyte proliferation as well as other effects, such as an increase of the number of circulating 
neutrophilic granulocytes $[44,45]$. In carp, the cortisol induced apoptosis in activated B lymphocytes [46] whereas it caused an inhibition of neutrophil apoptosis [47].

In fish, as in mammals, neutrophils play a primary role in the inflammatory process and are the first phagocytic cells to reach a site of tissue injury or infection [38]. The neutrophils are the most abundant circulating leukocyte in humans and zebrafish and are typically the first responders $[48,49]$. Moreover, neutrophils can increase rapidly in circulation during acute stress when cortisol levels are elevated [50]. We observed that in matrinxã, under physiological conditions, lymphocytes are the most abundant leukocytes. However, neutrophils observed in low number before bacterial inoculation become highly sensitive after acute infection, and increased significantly in the blood. In addition, at 6 hpi we observed an inverse association between the circulating neutrophils and the cortisol levels indicating the suppressor effect of glucocorticoids over the neutrophils populations. Fish of the $\beta-G 2$ group, with the highest cortisol levels, also had the lowest number of neutrophils. However, this association was not observed at $24 \mathrm{hpi}$. Cortisolinduced neutrophilia was observed also in channel catfish stressed by handling and transport [51].

Lastly, dietary $\beta-G 2$ induced a marked increase in the circulating monocyte population before bacterial challenge. Beta-glucans are considered as strong mitogens inducing proliferation of peripheral blood mononuclear cells [15]. However, the monocytes decreased after inoculation with $A$. hydrophyla, indicating that $\beta-G 2$ induced cellular migration to the site of infection. A similar finding was described in Pangasiodon hypophthalmus supplemented with $\beta$-glucan during 4 weeks [13]. Moreover, the profile of cortisol before the inoculation and at 6 hpi is associated with the profile of the circulating monocytes. In the physiological conditions, cortisol would be stimulating proliferation of these cells and the lower number of monocytes at $6 \mathrm{hpi}$, coincident with the highest cortisol levels observed, suggests the involvement of cortisol in the cell migration process as suggested by Tort (2011). Monocytes/ macrophages are part of the first line of defense cells from the innate immune system against infection and are also responsible for the regulation of inflammatory response [52,53]. Our results are in accordance to other studies describing the stimulator effect of $\beta$-glucan over monocyte functions [33].

The two different batches of Macrogard ${ }^{\circledR}$ we used promoted different results, the $\beta-G 2$ being the most efficient to stimulate cellmediated immunity of matrinxã. This has occurred with the use of different $\beta$-glucans which vary in purity, solubility, primary structure, molecular weight, branching and polymer charge, which have been shown to influence their activity [54,55]. The binding to different cellular receptors has been implicated in these activities [16]. Although not yet fully understood, these attributes influence the way the carbohydrates interact with their receptors. Similarly to our experiment, a study tested the effects of adding two different glucans ( $\beta-G 168.5 \%$ pure; $\beta-G 255.5 \%$ pure, both from Saccharomyces cerevisiae) into commercial feed of dogs to measure immune indicators. The study found that the two glucans had significant immunomodulating effects, but suggested that $\beta-G 1$ activity was superior to that of $\beta-G 2$ [18]. According to the authors, the samples of glucans were developed using two different biotechnological processes. Moreover, a recent study with Nile tilapia (Oreochromis niloticus) fed with diets containing the same two $\beta$-glucan molecules ( $\beta$-G 1 and $\beta-G$ 2) of the anterior work cited showed that the $\beta$-glucans have different magnitudes of effects on growth performance and the immune response. Specifically, even with a similar survival rate, the $\beta-G 1$ showed higher immunostimulation than $\beta-G 2$, although $\beta-G 2$ had improved the fish growth [19].

In summary, in matrinxã, $\beta-G 2$ was more efficient to stimulate the immune response cellular indicators and cortisol serum levels prior to and during an experimental acute infection. In addition, we observed an association of cortisol levels and immune response that indicate glucan-induced cortisol improves the start of the early immune response in matrinxã. Our results allow us to suggest that inclusion of $\beta-G$
2 in fish diet may help to prepare them to face stressful practices in fish farming.

\section{Acknowledgement}

The authors would like to thank the Centro de Aquicultura (CAUNESP) for supplying the fish for the research and the Laboratorio de Microbiologia e Parasitologia de Organismos Aquáticos (LAPOA), UNESP, Jaboticabal, São Paulo, Brazil, for supplying the bacteria culture. The first author was granted a $\mathrm{PhD}$ scholarship from the Asociación Universitaria Iberoamericana de Postgrado, Spain ( $\mathrm{n}^{\circ}$ 151185-1), through the program PAEDEX from Universidade Estadual Paulista UNESP.

\section{References}

[1] J. Romero, Antibiotics in aquaculture-use, abuse and alternatives, Health Environ. Aquac. (2012) 159-198 Chapter 6 www.intechopen.com.

[2] R.A. Dalmo, J. Bøgwald, ß-Glucans as conductors of immune symphonies, Fish Shellfish Immunol. 25 (2008) 384-396.

[3] V. Vetvicka, L. Vannucci, P. Sima, The effects of $\beta$-glucan on fish immunity, N. Am. J. Med. Sci. 5 (2013) 580-588.

[4] S.H. Hoseinifar, C.M. Caipang, Short-chain fatty acids as feed supplements for sustainable aquaculture: an updated view, Aquacult. Res. 48 (2017) 1380-1391.

[5] A. Nawaz, J.A. Bakhsh, S. Irshad, S.H. Hoseinifar, S. Xiong, The functionality of prebiotics as immunostimulant: evidences from trials on terrestrial and aquatic animals, Fish Shellfish Immunol. 76 (2018) 272-278.

[6] D.K. Meena, P. Das, S. Kumar, S.C. Mandal, A.K. Prusty, S.K. Singh, M.S. Akhtar, B.K. Behera, K. Kumar, A.K. Pal, S.C. Mukherjee, Beta-glucan: an ideal immunostimulant in aquaculture (a review), Fish Physiol. Biochem. 39 (2013) 431-457.

[7] C.M. Douglas, Fungal beta(1,3)-D-glucan synthesis, Med. Mycol. 39 (Suppl 1) (2001) 55-66.

[8] A. Synytsya, M. Novak, Structural analysis of glucans, Ann. Transl. Med. 2 (2014).

[9] Y.K. Soo, J.S. Hong, Y.L. Yoon, K.H. Cho, K.R. Yong, Biomedical issues of dietary fiber ß-glucan, J. Kor. Med. Sci. 21 (2006) 781-789.

[10] V. Selvaraj, K. Sampath, V. Sekar, Administration of yeast glucan enhances survival and some non-specific and specific immune parameters in carp (Cyprinus carpio) infected with Aeromonas hydrophila, Fish Shellfish Immunol. 19 (2005) 293-306.

[11] F. Hong, J. Yan, J.T. Baran, D.J. Allendorf, R.D. Hansen, G.R. Ostroff, P.X. Xing, N.K. Cheung, G.D. Ross, Mechanism by which orally administered beta-1,3-glucans enhance the tumoricidal activity of antitumor monoclonal antibodies in murine tumor models, J. Immunol. 173 (2004) 797-806.

[12] H. Babayigit, C. Kucuk, E. Sozuer, C. Yazici, K. Kose, H. Akgun, Protective effect of beta-glucan on lung injury after cecal ligation and puncture in rats, Intensive Care Med. 31 (2005) 865-870.

[13] W. Sirimanapong, A. Adams, E.L. Ooi, D.M. Green, D.K. Nguyen, C.L. Browdy, B. Collet, K.D. Thompson, The effects of feeding immunostimulant $\beta$-glucan on the immune response of Pangasianodon hypophthalmus, Fish Shellfish Immunol. 45 (2015) 357-366.

[14] I. Bricknell, R.A. Dalmo, The use of immunostimulants in fish larval aquaculture, Fish Shellfish Immunol. 19 (2005) 457-472.

[15] S. Soltanian, E. Stuyven, E. Cox, P. Sorgeloos, P. Bossier, Beta-glucans as immunostimulant in vertebrates and invertebrates, Crit. Rev. Microbiol. 35 (2009) 109-138.

[16] G.D. Brown, S. Gordon, Fungal $\beta$-glucans and mammalian immunity, Immunity 19 (2003) 311-315.

[17] D. Akramien, A. Kondrotas, J. Did, K. Egidijus, Effects of $\beta$-glucans on the immune system, Medicina 43 (2007) 597-606.

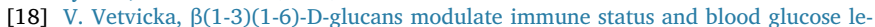
vels in dogs, Br. J. Pharmaceut. Res. 4 (2014) 981-991.

[19] F. Pilarski, C.A. Ferreira de Oliveira, F.P.B. Darpossolo de Souza, F.S. Zanuzzo, Different $\beta$-glucans improve the growth performance and bacterial resistance in Nile tilapia, Fish Shellfish Immunol. 70 (2017) 25-29.

[20] E.Z. Filho, D. Reynalte-Tataje, M. Weingartner, Potencialidad del género Brycon en la piscicultura brasileña, Rev. Colombiana Ciencias Pecuarias 19 (2006) 233-240.

[21] J.M. Tomás, The main Aeromonas pathogenic factors, ISRN Microbiol. (2012) 1-22.

[22] C.P. Wolkers, M. Serra, E.C. Urbinati, Social challenge increases cortisol and hypothalamic monoamine levels in matrinxã (Brycon amazonicus), Fish Physiol. Biochem. 41 (2015) 1501-1508.

[23] D.P. Anderson, A.K. Siwicki, Basic Hematology and Serology for Fish Health Programs, Asian Fisheries Society, 1995, pp. 185-202 Report; Diseases in Asian Aquaculture II; Anderson, D. P.; Siwicki, A. K., Fish Health Section.

[24] J.D. Biller-Takahashi, L.S. Takahashi, M.V. Saita, R.Y. Gimbo, E.C. Urbinati, Leukocytes respiratory burst activity as indicator of innate immunity of pacu Piaractus mesopotamicus, Braz. J. Biol. 73 (2013) 425-429.

[25] M. Tavares-Dias, F.R. Moraes, Caracteristicas hematologicas da Tilapia rendalli boulenger, 1896 (Osteichthyes: Cichlidae) capturada em "pesque-pague" de Franca, São Paulo, Brasil, Biosci. J. 19 (2003) 107-114.

[26] G. Jeney, M. Galeotti, D. Volpatti, Z. Jeney, D.P. Anderson, Prevention of stress in rainbow trout (Oncorhynchus mykiss) fed diets containing different doses of glucan, 
Aquaculture 154 (1997) 1-15.

[27] S. Soltanian, M.N. Adloo, M. Hafeziyeh, N. Ghadimi, Effect of B-Glucan on coldstress resistance of striped catfish, Pangasianodon hypophthalmus, Vet. Med. (Praha) 59 (2014) 440-446.

[28] E.M. Sternberg, G.P. Chrousos, R.L. Wilder, P.W. Gold, The stress response and the regulation of inflammatory disease, Ann. Intern. Med. 117 (1992) 854-866.

[29] L. Tort, Stress and immune modulation in fish, Dev. Comp. Immunol. 35 (2011) 1366-1375.

[30] S.V. Tsoni, G.D. Brown, Beta-glucans and dectin-1, Ann. N. Y. Acad. Sci. 1143 (2008) 45-60.

[31] P.P.L.M. Pepels, W.S.E. Bonga, P.H.M. Balm, Bacterial lipopolysaccharide (LPS) modulates corticotropin-releasing hormone ( $\mathrm{CRH})$ content and release in the brain of juvenile and adult tilapia (Oreochromis mossambicus; Teleostei), Gen. Comp. Endocrinol. 207 (2004) 4479-4488.

[32] R.Y. Gimbo, G.C. Fávero, L.N. Franco Montoya, E.C. Urbinati, Energy deficit does not affect immune responses of experimentally infected pacu (Piaractus mesopotamicus), Fish Shellfish Immunol. 43 (2015) 295-300.

[33] J. Ding, T. Feng, Y. Ning, W. Li, Q. Wu, K. Qian, Y. Wang, C. Qi, $\beta$-Glucan enhances cytotoxic T lymphocyte responses by activation of human monocyte-derived dendritic cells via the PI3K/AKT pathway, Hum. Immunol. 76 (2015) 146-154.

[34] V. Vetvicka, B.P. Thornton, G.D. Ross, Soluble beta-glucan polysaccharide binding to the lectin site of neutrophil or natural killer cell complement receptor type 3 (CD11b/CD18) generates a primed state of the receptor capable of mediating cytotoxicity of iC3b-opsonized target cells, J. Clin. Invest. 98 (1996) 50-61.

[35] D. Pietretti, N.I. Vera-Jimenez, D. Hoole, G.F. Wiegertjes, Oxidative burst and nitric oxide responses in carp macrophages induced by zymosan, MacroGard $\left({ }^{\circ}\right)$ and selective dectin-1 agonists suggest recognition by multiple pattern recognition receptors, Fish Shellfish Immunol. 35 (2013) 847-857.

[36] J.B. Jørgensen, G.J.E. Sharp, C.J. Secombes, B. Robertsen, Effect of a yeast-cell-wall glucan on the bactericidal activity of rainbow trout macrophages, Fish Shellfish Immunol. 3 (1993) 267-277.

[37] A.J. Shillitoe, The common causes of lymphopenia, J. Clin. Pathol. 3 (1950) 321-331.

[38] H. Øverland, E. Pettersen, A. Rønneseth, H. Wergeland, Phagocytosis by B-cells and neutrophils in Atlantic salmon (Salmo salar L.) and Atlantic cod (Gadus morhua L.), Fish Shellfish Immunol. 28 (2010) 193-204.

[39] J. Li, D.R. Barreda, Y.-A. Zhang, H. Boshra, A.E. Gelman, S. Lapatra, L. Tort, J.O. Sunyer, B lymphocytes from early vertebrates have potent phagocytic and microbicidal abilities, Nat. Immunol. 7 (2006) 1116-1124.

[40] M. Bagni, N. Romano, M.G. Finoia, L. Abelli, G. Scapigliati, P.G. Tiscar, M. Sarti,
G. Marino, Short- and long-term effects of a dietary yeast beta-glucan (Macrogard) and alginic acid (Ergosan) preparation on immune response in sea bass (Dicentrarchus labrax), Fish Shellfish Immunol. 18 (2005) 311-325.

[41] L.N. Franco-Montoya, T.P. Martins, R.Y. Gimbo, F.S. Zanuzzo, E.C. Urbinati, $\beta-$ Glucan-induced cortisol levels improve the early immune response in matrinxa (Brycon amazonicus), Fish Shellfish Immunol. 60 (2017) 197-204.

[42] T. Yada, T. Nakanishi, Interaction between endocrine and immune systems in fish, Int. Rev. Cytol. 220 (2002) 35-92.

[43] J. Harris, D.J. Bird, Modulation of the fish immune system by hormones, Vet. Immunol. Immunopathol. 77 (2000) 163-176.

[44] C.F. Ellsaesser, L. Clem, Cortisol-induced hematologic and immunologic changes in channel catfish (Ictalurus punctatus), Comp. Biochem. Physiol. Part A Physiol. 87 (1987) 405-408.

[45] A.K. Davis, D.L. Maney, J.C. Maerz, The use of leukocyte profiles to measure stress in vertebrates: a review for ecologists, Funct. Ecol. 22 (2008) 760-772.

[46] F.A. Weyts, G. Flik, B.M.L.V. Kemenade, Cortisol inhibits apoptosis in carp neutrophilic granulocytes, Dev. Comp. Immunol. 22 (1998) 563-572.

[47] F.A. Weyts, G. Flik, J.H.W. Rombout, B.M.L.V. Kemenade, Cortisol induces apoptosis in activated B cells, not in other lymphoid cells of the common carp, Cyprinus carpio L. Dev. Comp. Immunol. 22 (1998) 551-562.

[48] B. Amulic, C. Cazalet, G.L. Hayes, K.D. Metzler, A. Zychlinsky, Neutrophil function: from mechanisms to disease, Annu. Rev. Immunol. 30 (2012) 459-489.

[49] E. Harvie, A. Huttenlocher, Neutrophils in host defense: new insights from zebrafish, J. Leukoc. Biol. 98 (2015) 1-15.

[50] F.A. Weyts, B.M. Verburg-van Kemenade, G. Flik, Characterisation of glucocorticoid receptors in peripheral blood leukocytes of carp, Cyprinus carpio L, Gen. Comp. Endocrinol. 111 (1998) 1-8.

[51] C.F. Ellsaesser, L.W. Clem, Haematological and immunological changes in channel catfish stressed by handling and transport, J. Fish. Biol. 28 (1986) 511-521.

[52] A.E. Ellis, The leucocytes of fish: a review, J. Fish. Biol. 11 (1977) 453-491.

[53] Q. Chen, X.-J. Lu, J. Chen, Identification and functional characterization of the CSF1R gene from grass carp Ctenopharyngodon idellus and its use as a marker of monocytes/macrophages, Fish Shellfish Immunol. 45 (2015) 386-398.

[54] J.A. Bohn, J.N. BeMiller, ( $1 \rightarrow 3)-\beta-D-G l u c a n s$ as biological response modifiers: a review of structure-functional activity relationships, Carbohydr. Polym. 28 (1995) 3-14.

[55] F.Y. Kagimura, M.A.A. Cunha, A.M. Barbosa, R.F.H. Dekker, C.R.M. Malfatti, Biological activities of derivatized D-glucans: a review, Int. J. Biol. Macromol. 72 (2015) 588-598. 